\title{
Pemanfaatan Potensi Sumberdaya Manusia. Tinjauan Ruhaniah dan Budaya
}

\author{
Oleh : Ahmad Sahirul Alim
}

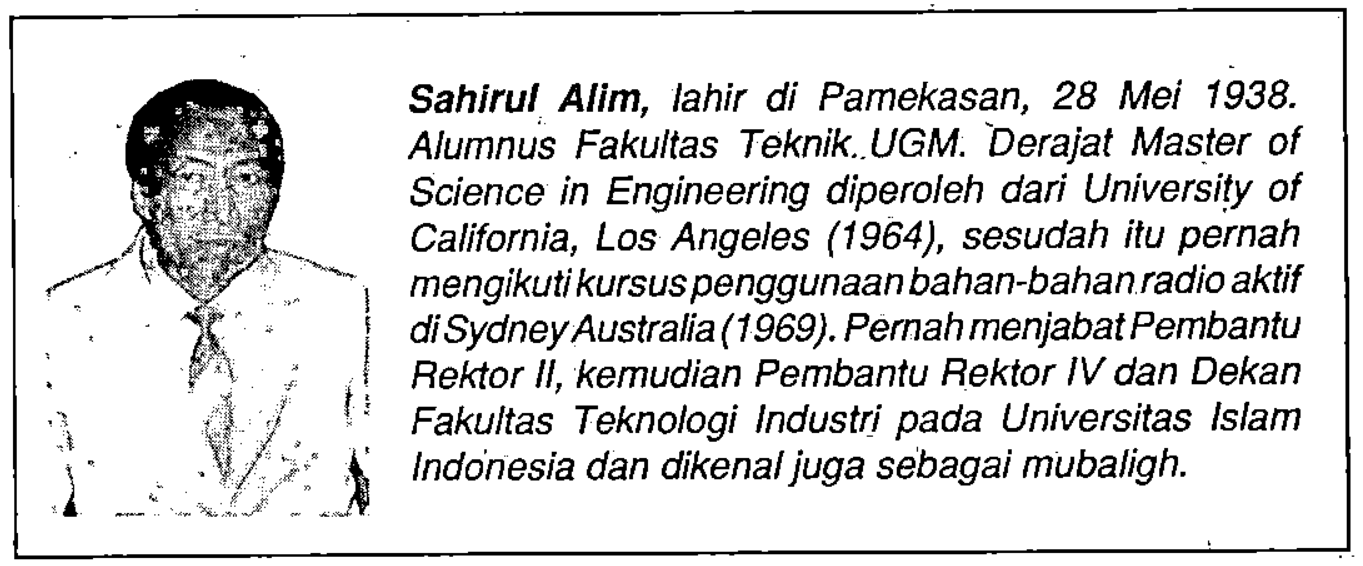

Manusia adalah ciptaan Allah SWT yang sangat istimewa di muka bumi. Kejadiannya diumumkan secarakhusus oleh Allah SWT di hadapan para malaikat dan diberi olehNya status sebagai khalifah di bumi (Q.Al Baqarah ayat 30). Untuk dapat Iebih memahami keistimewaan potensi manusia ini perlulah kita merenungkan kembali firman-firman allah berikut:

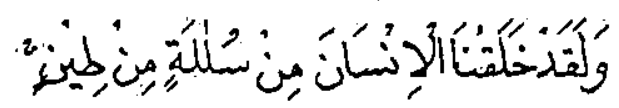

"Dan sesungguhnya kami telah menciptakan manusia dari suatu saripati (yang berasal) dari tanah" (Q.AlMu'minún :12)

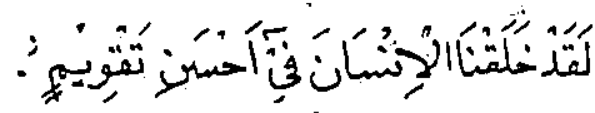

"Sesungguhnya Kami telah menciptakan manusia dalam struktur yang sebaikbaiknya" (Q. At Tin : 4)

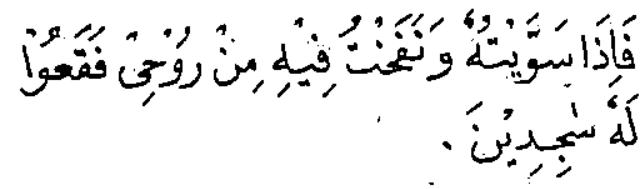

"MakaapabilaÁkutelahmenyempurnakan kejadiannya, dan telah meniupkan kedalamnya ruh (ciptaan)-Ku, maka tunduklah kamu kepadanya dengan bersujud" (Q. Al Hijr : 29)

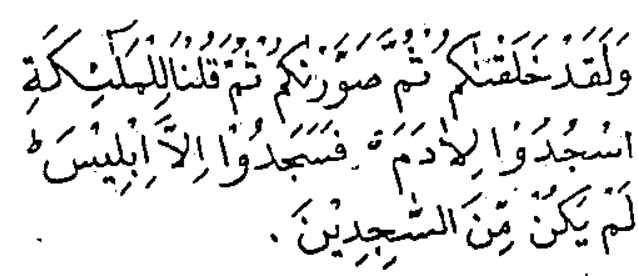

"Dan sesungguhnya" Kami telah menciptakan kamu, kemudian Kami beri kamu bentuk, lalu kami berkata kepada paramalaikat:: "Sujudlah (yaitu tunduklah) kamu kepada Adam", maka merekapun 
bersujud kecuali iblis. Dia tidak termasuk diantara orang-orang yang bersujud". $(Q$. Al A'raf : 1 l)

Keistimewaan manusia menurut ayat-ayat di atas disamping terletak pada postur dan struktur badannya yang serba indah, seimbang, lincah dan kuat, juga bahkan terutama terletak pada karunia Allah yang khas yaitu ruh insaniyah yang dinisbahkan kepada-Nya. Jadi, ada potensi ruhäniyang sangat istimewa disamping potensi ragawi (jasmani) pada diri kita semua. Ruh inilah yang membuat manusia mampuuntukmemakrifati Allah SWT yang mempunyai nama-nama yang serba indah (Al Asma'ul Husna) yang telah menciptakannya dan memeliharanya dengan penuh kasih sayang. Ruh inilah yang oleh Allah, setelah dipadukan dengan jazad yang serasi dan harmonis, diberi tanggungjawabamanat agarmengamalkan agama Islam dengan sungguh-sungguh dan ikhlas. Perhatikan lagi firman Allah berikut ini :

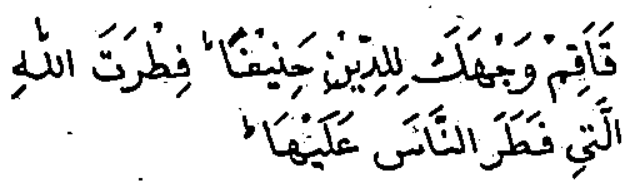

Maka hadapkanlah wajahmu dengan lurus kepada agama itu : itulah fitrah Allah yang telah menciptakan manusia menurut fitrah itu" (Q. Ar Rum : 30)

Kita semuamemaklumi bahwa hidup manusia ini pada dasamya berpangkal pada potensi ruhani. Maka sudah seharusnyalah bahwa kehidupan beragama yang wajib kita tegakkan itu adalah kehidupan yang berdasarkepada dan memanfatkan potensipotensi pokok ruhani-kita. Setelah kita renungkan secara mendalam, dapat disimpulkan bahwa manusia dilahirkan dengañ dibekali tigā kemampuan (potensi) pokok ruhani, yaitu berfikir, merasa dan percaya. Tiga potensi pokok ini kita sebut rasio, rasa dan iman secara berturut-turut. Ketiga potensi itu sebenamya merupakan satu kesatuan yang bulat, yang harus dibina dan dikembangkan secara bersamaan dan seimbang. Kesatuan yang bulat dari tiga potensi ruhani itu, yaitu rasio, rasa dan iman, di dalam Al Qur'an disebut fuad yang dapat diterjemahkan sebagai akal, akal-budi atau hati-nurani. Istilah "akal" ini terdapat dalam hadits-hadits Nabi Muhammad SAW, jangan dikacaukan dengan istilah rasio dalam bahasa barat: Dalam bahsa Arab, perkataanrasio ini adalah sama dengan ra'yu. Maka untuk selanjutnya istilah "akal" kita gunakan untuk menterjemahkan istilah fuad dalam $\mathrm{Al}$ Qur'an (baca: Q. An Nahl : 78).

Sekarang fuad (akal) itu dapat kita pandang terdiri dari tiga faset : rasio, rasa dan iman. Jadi orang yang hanya rasional saja berarti belum sempurna akalnya. Pengembangan kegiatan-kegiatan rasio (logika penalaran) dalami satu sistematika yang teratur dan terarah akan memberikan hasil yang disebut sains dan teknologi (saintek. atau iptek). Pengembangan eskpresi (ungkapan) rasa akan melahirkan seni (art). Adapun pengembangan potensi iman akan membuahkan aqidah, akhlak dan syari'ah.

Sudah disebutkan di muka bahwa akal (fuad) itu sebenamya adalah satu kesatuan yang utuh. Rasio, rasa, dan iman itu saling erat berhubungan satu sama lain, bahkan saling tumpang-tindih (overlap). Penekanan kegiatan oleh satu faset akal itu akan membiawa kepada spesialisasi dalam bidang ilmu tertentu. Jika titik berat kegiatan akal itu ada pada segi (faset) rasio, maka orang yang bersangkutan akan berkembang 
menjadi scientist. Jika titik berat kegiatan akal ada pada segi rasa, maka orang yang bersangkutan akan berkembang menjadi seniman. Jika fokus kegiatan akal itu terletak pada segi iman, maka orang yang bersangkutan akan berkembang menjadi ulama agama. Telah disebutkan diatas bahwa pembinaan dan pengembangan 3 faset akal itu harus bersamaan (simultan) dan seimbang sehingga orang yang bersangkutan sesuai denganfokus kegiatannya akan menjadi :scientist muslim yang saleh, atau seniman muslim yang bijaksana dan yang shufi, atau ulama Islam (yang cendikiawan). Mereka-mereka inilah orang-orangyang fuadnya (akalnya) dididik dan dikembangkan dalam kehidupan beragama Islam, merupakaninsan pembangunan sejati dn khalifah di bumi yang mampu menegakkan kebudayaan, yang stinggi-tingginya dan mampu mengislamkan kebudayaannya itu sehingga akan menjadi teladan bagi seluruh umat manusia.

Maka sumberdaya manusia hanya akan mendatangkan manfaat yang membahagiakan didunia dan diakhirat jika dididik dan dikembangkan dalam lingkungancahaya Allah, yaitu lingkungan kehidupan beragama Islam.

Perhatikan'firman Allah :

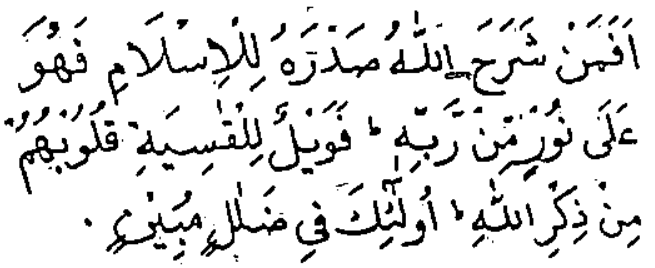

"Maka apakah orang-orang yang dibukakan Allah hatinya untuk menerima agama Islam lalu ia mendapat cahaya dari Tuhannya (sama dengan orang yang membatuhatinya)? Makakecelakaan yang besarlahbagi mereka yang telah membatu hatinya untuk mengingat Allah. Mereka itu dalamkesesatanyang nyata" (Q.Az.Zumar :22)

Seterusnya akan menjadi tugas kita yang tak henti-hentinya untuk memelihara dan mengembangkan kehidupan beragama yang telah diwariskan Nabi Muhammad SAW, di muka bumi ini secara sungguh-sungguh, sambil menjaganya dari segala rongrongan dan gangguan, sebab hanya itulah satu-satunya kehidupan yang berarti dan benar. Perhatikanlah pula firman Allah berikut :

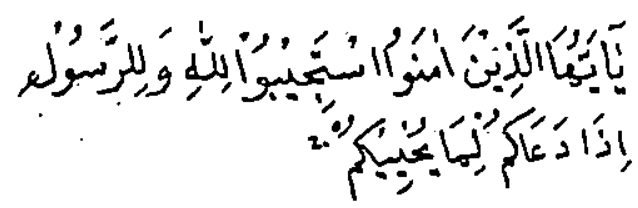

"Hai orang-orang yang beriman! Terimalah seruan Allah dan Rasul-Nya apabila ia memanggil kamu kepada apa yang menghidupkan kamu". (Q. Al-Anfal : 24)

Dapat disimpulkan, bahwa kehidupan beragama Islam itu sebenarnya adalah kehidupan, yang dihidupkan oleh cahaya wahyu ilahi yang menerangi fuad (akal atau ahti nurani), yaitu rasio, rasa dan iman sebagai satu kesatuan yang bulat dan utuh, sehingga terlaksana tuntunan hidup (hidayah) yang diajarkan oleh Allah danRasul-Nya seperti yang terfaham dari Q. Az-Zumar : 22 dan Q. Al-Anfal : $24 \mathrm{di}$ atas. Jadi, Islam didatangkan Allah untuk menyempurnakan fungsi dan perkembangan fuad sehingga manusianya menjadi insan mukmin sejati. Maka fuad itu merupakan anugerah Allah pada setiap manusia yang paling besár dan utama sehingga wajib disyukuri secara benar dan sungguh-sungguh. Renungkanlah firman Allah berikut ini : 


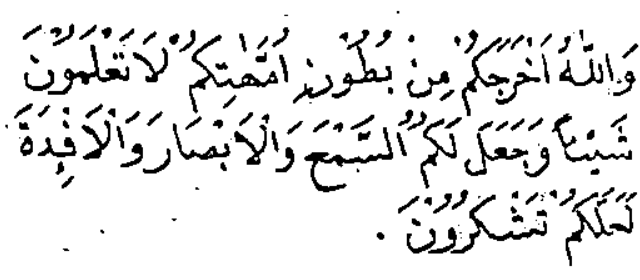

"Dan Allah mengeluarkan kamu dari perut ibumu dalam keadaan tidak mengetahui suatu apapun, dan Dia memberi kamu pendengaran, penglihatan dan fuad, agar kamu bersyukur" (Q. An Nahl : 78)

Maka Allah SWT menurunkan wahyu Al Quran dengan susunan dan gaya bahasa yang luar biasa indahnya dan mengandung pokok-pokok ilmu yang lengkap dan sangat mendalam sehingga bernilai sebagai mukjizat yang akliah dan iimiah, dimaksudkan untuk menghidupkan fuad dan menggugahnya secara efektif dan integrai; jadi untuk menyuburkan perkembangan rasio, rasa dan iman itu ke arah kesempurnaannya.

Sebagai suatu contoh tentang hal ini penulis mengambil firman Allah berikut :

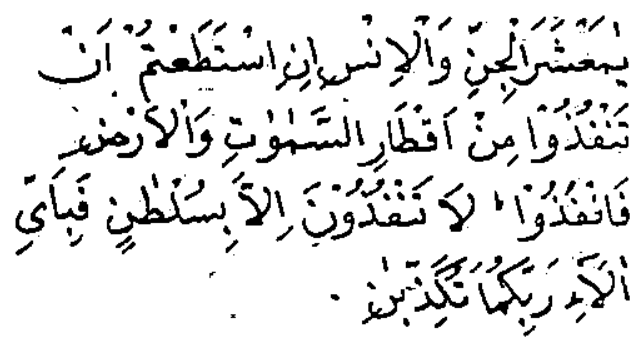

"Hai himpunanjindanmanusia,jika kamu sanggup menembusi (melintasi) penjuru langit dan bumi, maka tembusilah; kamu akan tidak akan dapat menembusinyamelainkan dengan sulthan (power). Maka nikmat Tuhan kamu yang manakah yang kamu hendak dustakan?" (Q. Ar-Rahman: 33,34)
Tidak diragukan lagi, ahwa firman, di atas benar-benar menggugah rasio, merangsang rasa dan meningkatkan iman secara serentak dan integral (terpadu). Secara sederhana dapat penulis mencoba menjelaskannya sebagai berikut:

\section{a. Menggugah rasio}

Manusia di dalam benaknya tentu dihinggapi pertanyaan : dapatkah melintasi langit sehingga mencapai bulan, planetplanet dan seterusnya untuk tidak kembali ke bumi atau pulang kembali dengan selamat ke bumi setelah waktu terteritu? Ayat di atas menyatakan bahwa fikiran/. pertanyaan semacam itu tidak mustahil untuk terlaksana. Allah mempersilahkan manusia untuk mencari jawabannya secara rasional dengan metoda penalaran dan eksperimen terhadap sifat-sifat dan hukumhukum yang dimiliki/mengatur bendabenda alam seperti difirmankan oleh-Nya.

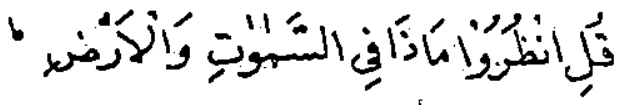

"Katakanlah: Nalarilah apa yang ada di langit dan di bumi" (Q. Yunus : 101)

Allah memberikan pentunjuk penting dalam ayat Ar-Rahman : 33 tersebut, yaitu kalau manusia ingin sukses pulang pergi kelangit, ia harus menyediakansulthan. Istilah "sulthan" ini dapat diartikan "power" dalam bahsa Inggris, yaitu kekuatan-kekuatan yang terorganisir, terkoordinasikan dan terarah untuk mencapai tujuan tertentu. Ingat saja pada perkataan "sulthan" yang dapat juga digunakan sebagai gelar rajaraja Islam. Seorang sulthan (sultan, raja) adalahfigurpuncak (tertinggi) dalam organisasi kerajaannya (negaranya).Ia harus mampu mengorganisir sumberdaya manusia, șumberdaya alam dan segala dana yang ada di bawah kekuasannya dengan 
sebaik-baiknya sedemikian rupa sehingga terarah untuk mencapai cita-cita luhur bangsanya (kaumnya).

Maka usaha untuk melintasi langit adalah bukan usaha kecil yang bisa dilakukan oleh perorangan atau duaan, tetapi usaha itu harus dikerjakan oleh suatu organisasi raksasa yang kuat dan teratur rapi, meliputi : pakar-pakar iptek, sumberdaya manusia yang terampil, taqwa serta cerdas, sumberdaya alam, energi, dana yang besar danindustri-industri pendukung yang diperlukan. Sebagai contoh adâlah NASA (National Aeronautics and Space Administration) yang dibangun oleh Amerika Serikat sehingga berhasil membuat missi Apollo 11 mendàrat di permukaan bulan dan ketiga orang astranoutnya pulang ke bumi dengan selamat. Jadi, Nasa itu berhasil menyediakan "sulthan" yang diperlukan untuk melintasi langit. Sebagai gambaran tentang besamya NASA, penulis dapat mengemukakan beberapa data berikut. Apollo 11 itu dibuat oleh 300.000 orang Amerika yang didukung oleh 20.000 industri AS. Satu missi ini saja telah menghabiskan biaya 355.000 .000 dollar AS. Seluruh program Apollo sampai waktu itu menelan biaya 21,2 milyar dollar AS. b. Menyentuh dan merangsang rasa

Susunan dan gaya bahasa Al Quran itu sendiri sudah merupakan mukjizat yang sangat kuat mempengaruhi rasa dalam kalbu. Manusia dibawa hanyut dalam lautan kebesaran dan kekuasaan Allah yang tidak terbatas di seluruh penjuru alam semesta. manusia disadarkan bahwa dirinya itu sebenamya hanya sangat kecil dan sangat lemah di hadapan Sang Maha Pencipta -sehinga sangat tidak layak untuk menyombongkan diri. Manusia harus tunduk dan tawadhuk serta banyak bersyukur kepada Khaliqnya.

\section{c. Meningkatkan iman}

Setelah manusia menyaksikan kebenaran firman-Nya dan silau memandang bekasan-bekasan sifat-sifatNya di seluruh jagad ciptaan-Na maka imannya akan bertambah kuat dan mendalam. Manusia akan merasa mudah sekali untuk mengerti dan meghayati bahwa Allah itu Maha Esa, Màha Berkuasa dan Maha Bijaksana, Maha Pengasih dan Maha Penyayang, Makrifatnyakepada Allah akan makin tinggi!

Demikianlah sekedar uraian sederhana untuk meyakinkan kita semua bahwa agama Islam diturunkan Allah memang untuk menyempumakan fitrah manusia dan untuk kebahagaiannya yang hakiki dan abadi. Kalau potensi-potensi fuad : rasio, rasa dan iman telah terlatih untuk bekerja sama secara terpadu dalam suatu jalinan, yang kokoh pada diri seseorang, maka penglihatan orang itu tidak hanya terbatas pada kemampuan melihat secara visual, tetapi juga mampu melihat secara batiniah. Dengan demikian maka peristiwa-peristiwa alam sekitamya tidak hanya ditafsirkan sebagai gejala fisik material saja tetapi difahamkan pula sebagai bekasan dari sifat-sifat Allah. Demikian pula dengan pendengarannya, tidak hanya terbatas pada sekedar kemampuan menangkap variasi gelombang gelombang bunyi, tetapi juga mampu mendengar pesan dan amanat dari Allah SWT. Maka dengan kehidupan beragama manusia tidak hanya merasakan kesenangan hidup biologis yang bersifat lahiriah, tetapi juga mampu menikmati kebahagiaan hidup ruhaniahbatiniah yang lebih tinggi. Bahkan kehidupan beragama itu tidakhanya sekedar untuk memberikan kebahagiaan yang bersifat temporer di dunia ini, tetapi Allah 
SWT menjanjikanpula kelanjutan hidup bahagia yang abadi di taman firdaus. Perhatikan firman Allah SWT berikut :

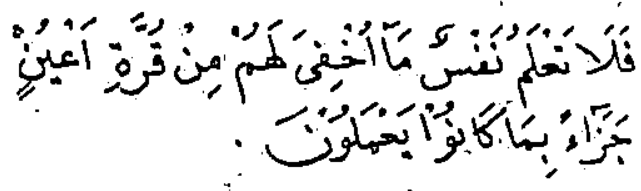

Seorang tidak mengetahui apa yang disembunyikan untuk mereka yaitu (bermacam-macam nikmat): yang menyedapkan pandangan mata sebagai balasan terhadap apa yang telah mereka kerjakan" (Q.As-Sajdah : 17)

Fuad yang telah kuat sempurna berkembang dalam siraman cạhaya hidayah Allah itu pasti akan mendapat pertolongan ilahi dalam mengatasi tekanan dan godaan hawa nafsu dalam diri orang yang bersangkutan maupun godaan yang datang darisyaitan/iblis di luardirinya. Seandainya ia tergelincir juga ke dalam dosa, maka Allah SWT akan membimbingnya kembali ke jalan yang benar dengan bertaubat yang ikhlas, sesuai firman-Nya :

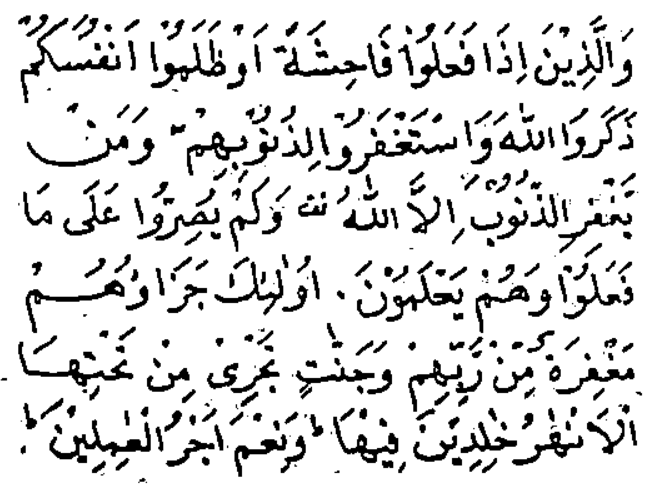

"Dan orang-orang yang apabilà mengerjakan perbuatan keji atau menganiaya diri sendiri, mereka (segera) ingat akan Allah, lalu memohon ampun terhadap dosa-dosamereka;dansiapa lagi yang dapat mengampuni dosa-dosa selain
Allah? Dan mereka tidak meneruskan perbuatan kejinya itu, sedang mereka mengetahui. Mereka itu balsannya ialah ampunän daari Tuhan mereka dan surga yang di dalamnya mengalir sungai-sungai, sedang mereka kekal di dalamnya; dan itulah sebaik-baikpahala orang-orangyang beramal. (Q. Ali imaran : 135,136)

Insan-insan yang beriman dan bertakwa sesuai dengan tuntunan/ajaran Islam itu tentu akan mengisi bumi dengan nilai-nilai budaya yang sarät iman dan akhlak luhur. Mereka itu adalah khalifah yang sekaligus hamba Allah yang hakekat fungsinya adalah hanya untuk mengibadati Allah semata. Mereka bekerja keras untuk memakmurkan bumi dan menegakkan kebudayaan yang setinggi-tingginya dalam batas-batas yang diizinkan Allah. Hal ihwal keduniaan mereka akan diatur pertamatama dengan memperbaiki akhlak setiap orang,lalu mengaturcarahidup berkeluarga dan membentuk suatu masyarakat yang sehat dengan anggota-anggota yang saling tolong menolong dan saling cintamencintai, yang pokok-pokok politiknya berdasarkan kepada prinsip-prinsip terbaik yang pernah dikenal oleh perikemanusiaan, dan sistem ekonominya dapat menjamin -keadilan sosial, sedangkan sistem sosialnya berdasarkan kepada persamaan hak dan kewajiban tanpa mengenal kasta-kasta. Selanjutnya masyarakat Islam ini dihubungkan dengan masyarakatmasyarakat yang lain atas dasar-dasar yang indah dan luhur untuk menciptakan hubungan internasional yang saling menguntungkan dan menyenangkan tanpa melanggàr atau menodai kehormatan masing-masing. 'Semuanya itu mereka kerjakan dalam rangka beramal saleh dan beribadah kepada Allah YME. 
- Banyak orang berpendapat bahwa unsur iman itu tidak diperlukan, tetapi orang akan dapat menyelesaikan semua persoalan hidupnya dengan saintek (iptek) dan seni (art) saja sehingga masyarakatnya akan sekular. Mereka ini tidak percaya kepada akhirat, hal ghaib, wahyu agama, alam barzakh dan sebagainya. Mereka hanya mengandalkan potensi rasio dan rasa saja. Konon mereka hanya berpegang kepada konsep bahwa manusia, homo sapiens, adalah produk evolusi dari pithecanthiropus erectus atau homo erectus, yaitu manusia kera yang sudah dapat berdiri dan berjalan tegak, yang hidup di muka bumi kira-kira satu juta tahun yang silam. Sebenamya Islam tidak mengandung ajaran yang, bertentangan dengan teori evolusi. Sebab homò erectus itu berasal dari tanah juga sehingga tidak perlu dipertentangkan dengan ayat $\mathrm{Al}$ Quran yang menyatakan bahwa manusia diciptakan dari tanah. Ini hanyalah masalah jasmaniah. Kondisi jasmani kita yang mirip kera tetapi lebih canggih darikera itu, menimbulkan potensi hawa nafsu hewaniah yang cukup canggih, yang kita rasakan keberadaannya dalam diri kita: Tetapi Allah kemudian menambahkan ruh khusus ciptaan-Nya ke dalam diri manusia yang akan mampu mengatasi sifat-sifat destruktif hawa nafsu hewaniah itu dan dijanjikan hidup kekal di -akhirat oleh-Nya. Maka makhluk manusia itu dilantik keberadaannya di depan para malaikat setelah memenangkan lombailmiah. Para malaikat diperintahkan untuk sujud hormat kepada Adam dan siap untuk melayaninya. Pelantikan ini sangat penting artinya, karena sekaligus merupakan maklumat ke seluruh jagad dari Allah SWT bahwa makhluk manusia ini tidak lagi berstatus hewan (zoon) tetap insan khalifah yang berstatus sangat istimewa. Di sinilah letak pentingnya wahyu ilahi untuk menyatakan kehendak Allah yang tidak bisa diketahui dengan sekedar metoda penalaran eksperimental dalam sains, sehingga faktor iman menjadi sangat esensial bagi manusia. Mengingkari iman berartị membiarkan diri kita terjerimus ke proses dehumanusasi yang menyebabkan kita kembali ke peri, kebinatangan, katakanlah hanya sebagai zoon politicon yang hanya peduli pada peri kehidupan duniawiah. Manusia akan 'beramai-ramai memperturutkan hawa-nafsu hewaniahnya dan akhimya akan runtuh binasa terjerumus ke dalam lembah siksa yang pedih. Renungkan dalam-dalam firman-firman Allah berikut :

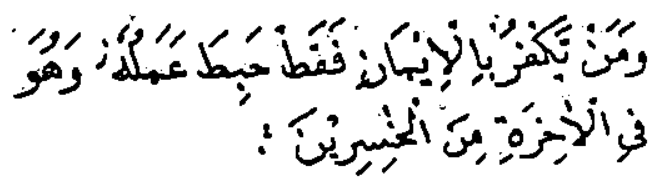

"Dan barangsiapamengingkari iman maka sungguh telah sia-sia amalnya, dan ia diakhiratakan tergolong orang-orang yang merugi" (Q. Al-Maidah : 5)

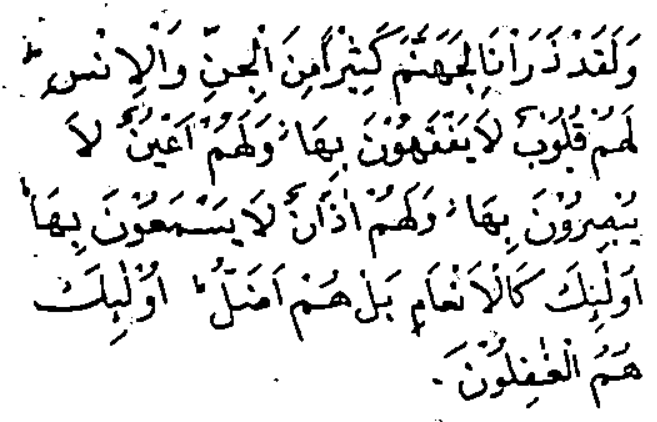

"Dan sesungguhnya Kami.jadikan untuk (isi) Jahanam kebanyakan dari jin dan. manusia; mereka mempunyai hati, (tetapi) tidakdigunakannya untukmemahami (ayatayat Allah), dan mereka mempunyai mata (tetapi) tidak dipakainya untuk melihat (tanda-tanda keberadaañ Allah), dan 
mereka mempunyai telinga (tetapi) tidak digunakannya untuk mendengarkan (ayatayat Allah). Mereka itu sebagai binatang ternak, bahkan mereka lebih sesat lagi. Mereka itulah orang-orang yang lalai". (Q. Al-A'raf : 179)

Peringatan Alliah dalam ayat-ayat di atas sangat jelas dan tajam mengisyaratkan bahaya proses dehumanisasi bagi mereka yang tidak beriman dengan ayat-ayat-Nya sehingga fuadnya menjadi jahil atau padam dan gelap. Proses dehumanisasi berarti proses dekadensi (kemerosotan) akhlak dan pengurangan (penurunan) rasa tanggungjawab seseorang, dan pada tingkatan tertentu akan menyeret manuasia ke dalam jurang kehinaan dan kehancuran. Dalam kaitan ini Allah berfirman :

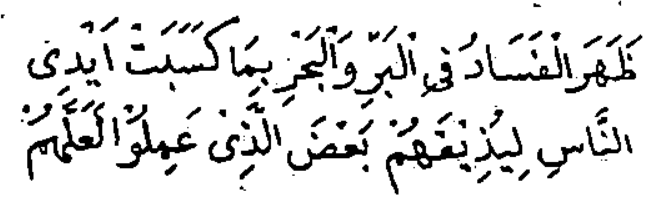

"Telah kelihatan kerusakan di darat dan di laut disebabkan oleh perbuatan tangan manusia, supaya Allah merasakan kepada mereka sebahagiaan dari (akibat) perbuatan mereka, agar mereka kembali (kejalan yang benar)". (Q. Ar-Rum : 41).

Maka - gerakkanlạh dan kembangkanlah kehidupan beragama Islam di mana saja kita berada agar kita selalu sukses dan bahagia, dalam rangka mencari ridha Allah SWT dan sekaligus mengamalkan dan mengamankan dasar negara kita Pancasila dan UUD 1945, menuju baldatun thayyibatun wa rabbun ghafur. Umat Islam yakni, bahwa hanya dengan kehidupan beragama yang sungguhsungguh maka Pembangunan Negara RI. yang kita cintai ini dapat sukses, dan ketahanan nasional serta persatuan dan kesatuan bangsa dan negara dapat ditingkatkan. 